\title{
Pengaruh Jumlah Jam Belajar dan Fasilitas Belajar terhadap Hasil Belajar Matematika Siswa SMP Negeru 4 Ajangale
}

\author{
Sumardin Raupu \\ Institut Agama Islam Negeri (IAIN) Palopo \\ Jl. Agatis, Kel. Balandai, Kota Palopo, Sulawesi Selatan, Indonesia \\ E-mail:aldhycool72@yahoo.co.id
}

Article History:

Received: $x x-x x-x x x x$; Received in revised form: $x x-x x-x x x x$; Accepted: $x x-x x-x x x x$;

Available online: $x x-x x-x x x x$

\begin{abstract}
The type of this research is expo facto research with the aims to determine whether the number of hours study and learning facilities affects to the student learning outcomes of mathematics in grade VIII SMP Negeri 4 Ajangale, Bone. The samples were taken in this research are 60 students from class VIII.A and VIII.B Lesson Year 2017/2018 by Cluster Random Sampling. The conclusion of this research is the number of student learning hours fall into enough category; Student learning facilities fall into less category and the student learning outcomes of mathematics into high category. The number of hours studied by observing the learning facility variables positively affects the student learning outcomes of mathematics with a value of $R 2$ is 0.142 . The learning facilities by observing the variable of learning hours did not positively affect the student learning outcomes of mathematics with the value of $R 2$ is 0,005. The number of learning hours and learning facilities together positively influenced to the st dent learning outcomes of mathematics with the value of R2 is 0.154 .
\end{abstract}

Keywords: The Number of Hours Studied; Learning Facility; The Student Learning Outcomes of Mathematics.

\begin{abstract}
Abstrak
Jenis penelitian ini adalah ekpost facto dengan tujuan untuk mengetahui pengaruh jumlah jam belajar dan fasilitas belajar terhadap hasil belajar matematika siswa kelas VIII SMP Negeri 4 Ajangale Kabupaten Bone Sulawesi Selatan. Jumlah sampel sebanyak 60 orang dari kelas VIII.A dan VIII.B Tahun Pelajaran 2017/2018. Sampel dipilih menggunakan Cluster Random Sampling. Kesimpulan dari penelitian ini yaitu, jumlah jam belajar siswa cukup, fasilitas belajar kurang, hasil belajar matematika siswa kategori tinggi. Jumlah jam belajar dengan memperhatikan variabel fasilitas belajar berpengaruh positif terhadap hasil belajar matematika siswa dengan R2 sebesar 0.142. Fasilitas belajar dengan memperhatikan variabel jumlah jam belajar tidak berpengaruh positif terhadap hasil belajar matematika siswa dengan R2 sebesar 0.005, Jumlah jam belajar dan fasilitas belajar secara bersamasama berpengaruh positif terhadap hasil belajar matematika siswa dengan R2 sebesar 0.154.
\end{abstract}

Kata Kunci: Jam Mengajar; Fasilitas Belajar; Hasil Belajar Matematika. 


\section{Pendahuluan}

Dalam meningkatkan mutu pendidikan matematika, maka salah satu indikator yang patut diperhatikan adalah prestasi belajar matematika di sekolah. Sedangkan untuk meningkatkan prestasi belajar tersebut perlu adanya pemantapan pengajaran matematika di sekolah, disamping itu perlu ditunjang oleh fasilitas belajar siswa dirumah. Sehingga prestasi belajar matematika di sekolah akan ditunjang oleh keaktifan belajar siswa dirumah. Jika fokus pembelajaran diarahkan pada keluarga, dimana keluarga memegang peranan penting dalam pembinaan di luar sekolah, maka faktor yang turut menentukan antara lain keadaan lingkungan keluarga dan waktu belajar dirumah. Kedua faktor ini terkait dengan tingkat keberhasilan anak dalam belajar matematika sehingga jika mendukung maka hasil belajarnya akan lebih baik demikian halnya jika tidak mendukung prestasi belajar anak akan lebih jelek.

Banyak siswa yang proses belajarnya terhambat karena kurangnya fasilitas belajar matematika yang dimiliki dirumah. Kemudian tidak jarang ditemui siswa kurang mampu mengatur, membagi dan memilih waktu belajarnya, khususnya memilih waktunya untuk belajar matematika yang lebih akomodatif dan fleksibel di luar sekolah. Serta, juga kurang mampu menyelesaikan pekerjaan rumah dengan terlalu sibuk bekerja di rumah, akibatnya waktu untuk belajar matematika dirasakan tidak cukup bahkan tidak sama sekali. Siswa yang hidup dalam keluarga besar sering menampakkan gejala dimana ia kurang mampu mengatur tempat belajarnya dan kurang memberi kenyamanan dalam belajar matematika karena sering dipakai bersama dengan anggota keluarga atau saudaranya.

Secara garis besar terdapat 2 faktor yang mempengaruhi proses belajar matematika yaitu faktor eksternal dan faktor internal. Faktor internal terdiri atas dua komponen yaitu: faktor fisik dan faktor psikis.

Faktor fisik: adalah faktor kesehatan pada diri anak yang belajar. Seorang anak akan mengalami gangguan belajar, jika kesehatannya terganggu. Agar anak dapat belajar dengan baik haruslah diusahakan kesehatannya tetap terjamin, karena anak yang sering terganggu 


\section{Pengaruh Jumlah Jam Belajar dan Fasilitas Belajar...}

kesehatannya tidak dapat belajar dengan stabil. Sedangkan faktor psikis: antara lain motivasi, minat, konsentrasi, disiplin, kebiasaan belajar, dan intelegensi.

Faktor eksternal yaitu faktor yang mempengaruhi siswa dalam belajar yang bersumber dari luar diri siswa, antara lain:

1. Tempat belajar: Tempat belajar yang dimaksud adalah ketenangan, tempat tersendiri, bersih, cukup penerangan, ventilasi udara serta ruangan yang cukup memadai. Tempat belajar yang nyaman turut menunjang terhadap prestasi yang akan dicapai siswa dalam belajar.

2. Alat pelajaran: Belajar yang baik haruslah ditunjang oleh alat belajar yang memadai seperti buku yang memadai seperti buku pelajaran, literatur, alat tulis menulis dan sebagainya. Alat-alat pelajaran sangat besar pengaruhnya dalam rangka keberhasilan siswa. Alat merupakan segala sesuatu yang dapat digunakan dalam rangka mencapai tujuan pengajaran. Dalam proses pengajaran maka alat mempunyai fungsi sebagai pelengkap untuk mencapai tujuan.

3. Suasana Tenang: Suasana tenang waktu belajar dapat memberikan motifasi yang baik, karena dalam proses belajar yang demikian akan menentukan dan mempengaruhi hasil belajar anak. Suasana tenang dalam belajer erat kaitannya dengan tempat belajar dan hubungan dengan orang tua dengan anak yang sedang belajar.

4. Cara Hidup Lingkungan Masyarakat: Cara hidup tetangga disekitar rumah dimana seorang anak tinggal, mempunyai pengaruh yang besar terhadap pertumbuhan dan perkembangan anak-anak yang berada pada lingkungan masyarakat yang rajin belajar, secara sistematis anak akan terpengaruh dan akan rajin belajar. Lingkungan yang ditata secara bagus untuk mendukung belajar harus dilakukan karena belajar itu segar, hidup penuh semangat atau datang dan jelajahi ${ }^{1}$.

1 Pupuh Fathurrohman and Sobry Sutikno, Strategi Belajar Mengajar (Jakarta: PT Refika Aditama, 2011). 
Banyaknya waktu yang digunakan untuk belajar sangat berpengaruh terhadap hasil belajar. ${ }^{2}$ Disamping kualitas jam belajar diluar jam pelajaran juga perlu mendapat perhatian yang sungguh-sungguh dari pihak orang tua sehingga kegiatan belajar diluar jam pelajaran dapat berlangsung dengan baik, dalam arti dilakukan secara disiplin dan teratur serta dilakukan pada waktu yang tepat sesuai teori belajar, sehingga kegiatan belajar diluar jam pelajaran dapat secara maksimal membangkitkan terjadinya proses belajar dalam diri anak yang bersangkutan.

Fasilitas adalah jawaban tepat fungsi-fungsi belajar ${ }^{3}$. Fasilitas belajar mencakup semua benda yang diperlukan dalam melakukan kegiatan belajar yang dapat menunjang dalam pencapaian perubahan sikap setiap indifidu yang belajar. Fasilitas belajar yang dimaksud disini mencakup semua peralatan belajar.

Fasilitas belajar matematika mempunyai hubungan yang signifikan dengan hasil belajar matematika ${ }^{4}$. Hal serupa juga diungkapkan dari hasil penelitian bahwa fasilitas belajar memiliki pengaruh positif terhadap prestasi belajar matematika siswa kelas IX SMA Negeri 4 Parepare ${ }^{5}$. Dari pendapat tersebut maka jelas bahwa fasilitas belajar siswa turut menenukan cara belajar siswa. Faslitas belajar yang cukup akan memungkinkan memperlancar penguasaan siswa terhadap mata pelajaran yang dipelajarinya, memungkinkan memberikan kesempatan yang luas bagi siswa untuk melakukan kegiatan belajar yang teratur dan akan menimbulkan suasana yang menyenangkan dan menggairahkan bagi diri siswa untuk berprestasi baik.

2 Djaali, Tes Validitas Dan Reliabilitas (Ujung Pandang: IKIP Ujung Pandang, 1985).

${ }^{3}$ Abu Ahmadi and dkk, Psikologi Belajar (Jakarta: Rineka Cipta, 2003), 40.

${ }^{4}$ Hairul, "Perbedaan Prestasi Belajar Matematika Yang Diajar Dengan Tipe Think Pair Share (TPS) Dan Yang Diajar Dengan Tipe Numbered Head Together (NHT) Siswa Kelas VIII SMP Negeri 2 Anggeraja Kabupaten Enrekang" (Skripsi, Universitas Muhammadiyah Parepare, 2008).

${ }^{5}$ Darmawati, "Pengaruh Iklim Keluarga Dan Minat Belajar Terhadap Prestasi Belajar Matematika Siswa Kelas IX SMU Negeri 4 Parepare” (2003). 
Dalam rangka penelitian ini tentunya tidak mungkin diteliti secara keseluruhan. Maka sesuai dengan apa yang diteliti oleh penulis, fasilitas belajar yang dimaksudkan adalah fasilitas belajar yang dimiliki oleh siswa diluar sekolah yang meliputi ruang belajar, meja belajar, peralatan alat tulis menulis, buku matematika SMA dan alat penerangan listrik.

Hasil belajar siswa dapat diketahui dengan melakukan evaluasi yaitu mengukur dan menilai hasil kinerja siswa ${ }^{6}$. Hasil belajar adalah kemampuan yang dimiliki siswa setelah ia menerima pengalaman belajar. Maka hasil belajar dibagi kedalam tiga kategori yaitu: a) keterampilan dan kebiasaan, b) pengetahuan dan pengertian, c) sikap dan cita-cita.

Berdasarkan hal tersebut, penulis merasa perlu melakukan suatu kajian yang lebih mendalam, yaitu dengan melakukan suatu penelitian untuk melihat apakah ada pengaruh faktor external dalam hal ini jumlah jam belajar matematika diluar jam pelajaran sekolah dan fasilitas belajar matematika dirumah terhadap hasil belajar matematika siswa kelas VIII SMP Negeri 4 Ajangale Kabupaten Bone.

\section{Metode}

Desain penelitian ini adalah penelitian ekspost facto yang bersifat korelasional, yang menyelidiki hubungan antara jumlah jam belajar (X1) dan fasilitas belajar (X2) sebagai variabel bebas dan hasil belajar (Y) sebagai variabel terikat. Populasi pada penelitian ini adalah seluruh siswa kelas VIII SMP Negeri 4 Ajangale Kabupaten Bone Tahun Pelajaran 2017/2018 yang terdiri dari 3 kelas pararel, sedangkan sampelnya adalah siswa kelas VIII.A dan VIII.в dengan total sampel sebanyak 60 siswa yang dipilih dengan teknik Cluster Random Sampling.

Teknik pengumpulan datanya adalah sebagai berikut:

1. Jumlah jam belajar $\left(\mathrm{X}_{1}\right)$ : Angket jumlah jam belajar digunakan untuk menanyakan banyaknya waktu (dalam jam seminggu) yang digunakan

\footnotetext{
${ }^{6}$ Hayatun Nufus et al., "Pengaruh Model Pembelajaran Kooperatif Tipe Numbered Head Together (NHT) Terhadap Hasil Belajar Matematika Siswa Kelas VII Berdasarkan Level Kemampuan Matematis," Al-Khwarizmi: Jurnal Pendidikan Matematika dan Ilmu Pengetahuan Alam 4, no. 1 (2016): 33, https://doi.org/10.24256/jpmipa.v4i1.250.
} 
untuk belajar matematika di rumah. Data hasil kategori jumlah jam belajar dianalisis dengan melihat distribusi frekuensi pada hasil analisis.

2. Fasilitas belajar $\left(\mathrm{X}_{2}\right)$ : Menggunakan kuesioner fasilitas belajar. Jumlah item16, tiap item disediakan jawaban Ya dengan skor 1 (satu) dan jawaban tidak dengan skor 0 (nol). Data hasil kategori fasilitas belajar belajar dianalisis dengan melihat distribusi frekuensi pada hasil analisis.

3. Hasil belajar matematika (Y): Menggunakan teknik dokumentasi berupa pencatatan hasil belajar siswa selama seminggu dengan menggunakan kategorisasi yang disusun oleh Depdikbud tahun 1993.

Teknik analisis data yang digunakan adalah sebagai berikut:

1. Analisis Statistik Deskriptif

a. Variabel Jumlah Jam Belajar: Pengukuran variabel jumlah jam belajar $\left(\mathrm{X}_{1}\right)$ menggunakan skala likert sebagai berikut ${ }^{7}$ :

\begin{tabular}{|c|c|c|c|c|}
\hline Sangat kurang & Kurang & Sedang & Cukup & \$angat cukup \\
\hline 27 & 30,7 & 36,2 & 40,6 & 52 \\
\hline
\end{tabular}

b. Variabel Fasilitas Belajar: Pengukuran variabel fasilitas belajar $\left(\mathrm{X}_{2}\right)$ menggunakan skala likert sebagai berikut :

\begin{tabular}{|c|c|c|c|c|}
\hline Sangat kurang & Kurang & Sedang & Cukup & \$angat cukup \\
\hline 5 & 6,6 & 8,1 & 9,1 & 16 \\
\hline
\end{tabular}

c. Variabel Hasil Belajar: Hasil belajar matematika (Y) menggunakan pengkategorian dengan skala lima yang disusun oleh Depdikbud tahun 1993 dimana skor standar umum yang digunakan yaitu8:

7 Sudjana, Evaluasi Hasil Belajar, Konstruksi, Dan Analisis (Bandung: Pustaka Martiana, 1986), 29.

${ }^{8}$ M Herniati, "Peningkatan Hasil Belajar Matematika Siswa Melalui Penberian Kuis Pada Awal Pembelajaran” (Skripsi, Universitas Muhammadiyah Parepare, 2008), 8. 
Pengaruh Jumlah Jam Belajar dan Fasilitas Belajar...

Skor 85 - 100 berada pada tingkat penguasaan "sangat tinggi"

Skor 65 - 84 berada pada penguasaan "tinggi"

Skor 55 - 64 berada pada tingkat penguasaan "sedang"

Skor 35 - 54 berada pada tingkat penguasaan "rendah"

Skor 0 - 34 berada pada tingkat penguasaan "sangat rendah"

2. Analisis Statistik Inferensial

Analisis yang digunakan adalah regresi linear berganda dengan persamaan regresi sebagai berikut:

$Y=\beta_{0}+\beta_{1} X_{1}+\beta_{2} X_{2}+\epsilon$

Keterangan:

$\mathrm{Y}=$ Skor hasil belajar matematika

$\mathrm{X}_{1}=$ Skor jumlah jam belajar yang dipergunakan siswa.

$\mathrm{X}_{2}=$ Skor fasilitas belajar siswa dalam belajar matematika

$\beta 0=$ Parameter konstanta (intercept)

$\beta 1=$ Parameter yang meenjelaskan hubungan antara X1 dan X2

$\beta 2=$ Parameter yang menjelaskan antara X2 dan $\mathrm{Y}$

$€=$ Error (komponen kesalahan acak)

\section{Hasil Analisis Statistik Deskriptif}

a. Variabel Jumlah Jam Belajar Matematika

Tabel.1 Statistik deskriptif skor jumlah jam belajar $\left(\mathrm{X}_{1}\right)$

\begin{tabular}{cc}
\hline Statistik & Nilai Statistik \\
\hline Ukuran sampel & 60 \\
Skor tertinggi & 52 \\
Skor terendah & 27 \\
Rentang skor & 25 \\
Skor rata-rata & 39,03 \\
Median & 38,00 \\
Modus & 43 \\
Standar deviasi & 5,79 \\
Skwennes & 168 \\
Kurtosis & -540 \\
\hline
\end{tabular}

Tabel 1 menunjukkan bahwa nilai skor tertinggi adalah 52 yang berada pada skor cukup tinggi, skor terendahnya adalah 27, rentang skornya adalah Al-Khwarizmi - 21 
25 , skor rata-ratanya adalah 39,03 dengan standar deviasi 5,79. Selanjutnya, jika data pada Tabel 1 dikategorikan dalam skala lima, diperoleh data seperti pada Tabel 2 berikut:

Tabel 2 Persentase skor jumlah jam belajar Matematika $\left(\mathrm{X}_{1}\right)$

\begin{tabular}{cccc}
\hline Interval skor & Kategori & Frekuensi & Persentase \\
\hline $47.6-52.0$ & Sangat Cukup & 5 & 8.3 \\
$40.6-47.5$ & Cukup & 20 & 33.3 \\
$36.2-40.5$ & Sedang & 14 & 23.3 \\
$30.7-36.1$ & Kurang & 18 & 30.3 \\
$27.0-30.6$ & Sangat kurang & 3 & 5.0 \\
\hline \multicolumn{2}{c}{ Jumlah } & 60 & 100 \\
\hline
\end{tabular}

Berdasarkan Tabel 2 tersebut, dapat disimpulkan bahwa jumlah jam belajar siswa berada pada keadaan cukup dengan rata-rata 33.3 yang berada dalam interval 40.6 - 47.5.

b. Variabel Fasilitas Belajar Matematika

Tabel 3 Statistik deskriprif skor fasilitas belajar matematika

\begin{tabular}{cc}
\hline Statistik & Nilai statistik \\
\hline Ukuran sampel & 60 \\
Skor tertinggi & 52 \\
Skor terendah & 27 \\
Rentang skor & 25 \\
Skor rata-rata & 39,03 \\
Median & 38,00 \\
Modus & 43 \\
Standar deviasi & 5,79 \\
Skwennes & 168 \\
Kurtosis & -540 \\
\hline
\end{tabular}

Tabel 3 tersebut menunjukkan bahwa nilai skor tertinggi adalah 52 yang berada pada skor cukup tinggi, skor terendahnya adalah 27, rentang skornya adalah 25, skor rata-ratanya adalah 39,03 dengan standar deviasi 5,79. Dari keseluruhan responden terlihat bahwa minat belajar siswa dapat dikategorikan sebagai berikut: 
Tabel 4 Distribusi frekuensi dan persentase fasilitas belajar $\left(\mathrm{X}_{2}\right)$

\begin{tabular}{|c|c|c|c|}
\hline Interval skor & Kategori & Frekuensi & Persentase \\
\hline $13.1-16.0$ & Sangat cukup & 1 & 1.7 \\
\hline $9.1-13.0$ & Cukup & 17 & 28.8 \\
\hline $8.1-9.0$ & Sedang & 11 & 18.3 \\
\hline $6.6-8.0$ & Kurang & 26 & 43.3 \\
\hline $5.0-6.5$ & Sangat Kurang & 5 & 8.3 \\
\hline \multicolumn{2}{|c|}{ Jumlah } & 60 & 100 \\
\hline
\end{tabular}

Berdasarkan Tabel 4, dapat disimpulkan bahwa fasilitas belajar siswa berada dalam kategori kurang dengan rata-rata 43,3 yang berada dalam interval $6.6-8.0$.

c. Variabel Hasil Belajar Matematika

Tabel 5 Statistik skor Hasil Belajar Matematika (Y)

\begin{tabular}{cc}
\hline Statistik & Nilai statistik \\
\hline Ukuran sampel & 60 \\
Skor tertinggi & 87 \\
Skor terendah & 60 \\
Rentang skor & 27 \\
Skor rata-rata & 78,43 \\
Median & 38,00 \\
Modus & 43 \\
Standar deviasi & 5,79 \\
\hline
\end{tabular}

Tabel 5 tersebut menunjukkan bahwa nilai skor tertinggi adalah 87, skor terendahnya adalah 60 , rentang skornya adalah 27 , skor rata-ratanya adalah 78,43 dengan standar deviasi 5,79. Selanjutnya dikategorisasikan berdasarkan pengkategorian hasil belajar oleh Depdikbud tahun 1993, (Herniati, 2008: 24) sebagai berikut:

Tabel 6 Distribusi dan persentasi skor hasil belajar matematika (Y)

\begin{tabular}{cccc}
\hline Skor & Kategori & Frekuensi & Persentase \\
\hline $85-100$ & Sangat Tinggi & 2 & 3,3 \\
$65-84$ & Tinggi & 50 & 83,3 \\
$55-64$ & Sedang & 8 & 13,3 \\
$35-54$ & Rendah & 0 & 0 \\
$0-34$ & Sangat Rendah & 0 & 0 \\
\hline \multicolumn{4}{c}{ Jumlah } \\
\hline
\end{tabular}


Berdasarkan Tabel 6 tersebut, dapat disimpulkan bahwa hasil belajar matematika siswa berada dalam kategori tinggi dengan rata-rata 83.3 yang berada dalam interval 65 - 84. Tingkat kepercayaan diri kelas eksperimen berada pada kategori sedang dengan frekuensi sebesar 2 atau 6,66\% sampai dengan sangat tinggi dengan frekuensi 7 atau 23,33\%. Sedangkan kelas kontrol hanya berada pada kategori sedang dengan frekuensi 26 atau 86,66\% sampai kategori tinggi dengan frekuensi 4 atau 13,33\%. Hasil tersebut juga menunjukkan tingkat kepercayaan diri siswa pada kelas eksperimen berada pada dominan sebaran kategori tinggi. Berbeda dengan hal itu, kategori kepercayaan diri siswa pada kelas kontrol hanya berada pada dominan sebaran kategori sedang.

\section{Hasil Analisis Statistik Inferensial}

Sebagai persyaratan analisis, terlebih dahulu dilakukan uji normalitas dan linearitas. Hasil perhitungan dengan menggunakan program "SPSS 15" yang terdapat pada lampiran 2, jika $\mathrm{H}_{0}=$ data berasal dari populasi berdistribusi normal dan $\mathrm{H}_{1}=$ data tidak berasal dari populasi yang tidak berdistribusi normal. Dengan kriteria penolakan $\mathrm{H}_{0}$ bila $\mathrm{P}<\alpha$, diperoleh nilai peluang untuk variabel jumlah jam belajar $P=0,200$, untuk variabel fasilitas belajar $\mathrm{P}=0,000$ dan untuk variabel hasil belajar matematika $\mathrm{P}=0,184$. Dari taraf signifikansi $\alpha=0,05$, berarti $\alpha<$ P. karena $\alpha$ lebih kecil dari P, maka $\mathrm{H}_{0}$ diterima berarti hipotesis penelitian $\left(\mathrm{H}_{1}\right)$ ditolak. Sehingga dapat disimpulkan bahwa data jumlah jam belajar, fasilitas belajar, dan hasil belajar matematika siswa kelas VIII SMP Negeri 4 Ajangale Kabupaten Bone berasal dari populasi yang berdistribusi normal.

Uji linearitas regresi (uji kecocokan model) digunakan untuk menguji cocok atau tidaknya model linear yang digunakan, atau apakah ada hubungan linear antara peubah bebas dan peubah terikat. Berdasarkan hasil analisis inferensial bersifat linear. Dengan kriteria $\mathrm{H}_{0}$ diterima jika $\mathrm{P}>\alpha$, dari lampiran diperoleh nilai peluang untuk variabel jumlah jam belajar dan fasilitas belajar terhadap hasil belajar yaitu $\mathrm{P}=0,009$ dimana nilai $\mathrm{P}>\alpha=$ 


\section{Pengaruh Jumlah Jam Belajar dan Fasilitas Belajar..}

0,05 , artinya $\mathrm{H}_{0}$ diterima. Hal ini menunjukkan bahwa data tersebut memenuhi uji linearitas regresi.

Berdasarkan analisis dan output minitab diperoleh persamaan regresi linear multipel antara hasil belajar matematika dengan jumlah jam belajar dan fasilitas belajar sebagai berikut: $\hat{Y}=61.045+0.249 \mathrm{X}_{1}-0.217 \mathrm{X}_{2}$. hasil penolakan $\mathrm{H}_{0}$ jika $\mathrm{P}<\alpha$ maka $\mathrm{H}_{0}$ ditolak berarti $\mathrm{H}_{1}$ diterima. Hasil perhitungan pada lampiran diperoleh nilai $\mathrm{P}=0.009$ yang lebih kecil dari taraf signifikan $\alpha=0.05$. Hal ini menunjukkan $\mathrm{H}_{0}$ ditolak dan menerima $\mathrm{H}_{1}$. Jadi dapat disimpulkan bahwa fasilitas belajar dan jumlah jam belajar secara bersama-sama mempunyai pengaruh terhadap hasil beajar matematika siswa.

Dari hasil perhitungan juga diperoleh nilai koefisien determinasi $\left(\mathrm{R}^{2}\right)=$ 0.154 berarti $15.40 \%$ variasi hasil belajar dapat dijelaskan oleh jumlah jam belajar dan fasilitas belajar siswa. Angka tersebut menunjukkan kontribusi jumlah jam belajar dan fasilitas belajar terhadap hasil belajar matematika siswa kelas VIII SMP Negeri 4 Ajangale Kabupaten Bone.

Jumlah jam belajar matematika mempunyai pengaruh variabel fasilitas belajar. (nilai $p=0,002<\alpha=0.05$ ). Sebaliknya, tidak ada pengaruh fasilitas belajar terhadap hasil belajar matematika (nilai $\mathrm{p}=0,378>\alpha=0.05$ ). Hal ini disebabkan karena kurangnya kelngkapan fasilitas belajar siswa dirumah yang berupa buku paket pelajaran matematika, ruang belajar, lampu sebagai alat penerangan.

\section{Simpulan}

\section{Penutup}

Berdasarkan rumusan masalah, maka dapat ditarik kesimpulan sebagai berikut: (1) Jumlah jam belajar siswa kelas VIII SMP Negeri 4 Ajangale Kabupaten Bone yang dijadikan responden penelitian keadaannya cukup dengan R2 sebesar 0.142; (2) Fasilitas belajar siswa kelas VIII SMP Negeri 4 Ajangale Kabupaten Bone yang dijadikan responden penelitian termasuk kategori kurang dengan $\mathrm{R}^{2}$ sebesar 0.005; (3) Hasil belajar matematika siswa kelas VIII SMP Negeri 4 Ajangale Kabupaten Bone yang dijadikan responden 
penelitian termasuk kategori tinggi dengan $\mathrm{R}^{2}$ sebesar 0.154 ; (4) Jumlah jam belajar dengan memperhatikan variabel fasilitas belajar berpengaruh positif terhadap hasil belajar matematika siswa kelas VIII SMP Negeri 4 Ajangale Kabupaten Bone; (5) Fasilitas belajar dengan memperhatikan variabel jumlah jam belajar tidak berpengaruh positif terhadap hasil belajar matematika siswa kelas VIII SMP Negeri 4 Ajangale Kabupaten Bone; (6) Jumlah jam belajar dan fasilitas belajar secara bersama-sama berpengaruh positif terhadap hasil belajar matematika siswa kelas VIII SMP Negeri 4 Ajangale Kabupaten Bone.

Saran

Berdasarkan kesimpulan tersebut peneliti mengajukan saran agar dapat dijadikan bahan pertimbangan yaitu karena kepercayaan diri siswa berpengaruh terhadap keberhasilan akademik pada pembelajaran matematika siswa, maka diharapkan agar setiap sekolah khususnya MTs Satu Atap Sampano mampu menerapkan metode suggestopedia dalam menumbuhkan kepercayaan diri siswa pada proses pembelajaran matematika dan mata pelajaran lainnya sehingga siswa menjadi termotivasi dan aktif dalam kelas.

\section{Daftar Pustaka}

Ahmadi, Abu, and dkk. Psikologi Belajar. Jakarta: Rineka Cipta, 2003.

Darmawati. "Pengaruh Iklim Keluarga Dan Minat Belajar Terhadap Prestasi Belajar Matematika Siswa Kelas IX SMU Negeri 4 Parepare." Skripsi, 2003.

Djaali. Tes Validitas Dan Reliabilitas. Ujung Pandang: IKIP Ujung Pandang, 1985.

Fathurrohman, Pupuh, and Sobry Sutikno. Strategi Belajar Mengajar. Jakarta: PT Refika Aditama, 2011.

Hairul. "Perbedaan Prestasi Belajar Matematika Yang Diajar Dengan Tipe Think Pair Share (TPS) Dan Yang Diajar Dengan Tipe Numbered Head Together (NHT) Siswa Kelas VIII SMP Negeri 2 Anggeraja Kabupaten Enrekang." Skripsi, Universitas Muhammadiyah Parepare, 2008.

M Herniati. "Peningkatan Hasil Belajar Matematika Siswa Melalui Penberian Kuis Pada Awal Pembelajaran." Skripsi, Universitas Muhammadiyah Parepare, 2008.

Nufus, Hayatun, Rezi Ariawan, Erdawati Nurdin, and Hasanuddin Hasanuddin. "Pengaruh Model Pembelajaran Kooperatif Tipe 
Pengaruh Jumlah Jam Belajar dan Fasilitas Belajar...

Numbered Head Together (NHT) Terhadap Hasil Belajar Matematika Siswa Kelas VII Berdasarkan Level Kemampuan Matematis." AlKhwarizmi: Jurnal Pendidikan Matematika dan Ilmu Pengetahuan $\begin{array}{lllll}\text { Alam } & 4, & \text { no. } & 1 & \text { 29-42. }\end{array}$ https://doi.org/10.24256/jpmipa.v4i1.250.

Sudjana. Evaluasi Hasil Belajar, Konstruksi, Dan Analisis. Bandung: Pustaka Martiana, 1986. 
Halaman ini sengaja dikosongkan

Al-Khwarizmi - 28 